\title{
ENERGY EFFICIENCY FROM THE PERSPECTIVE OF DEVELOPING COUNTRIES
}

\author{
J. Goldemberga , T.B. Johansson ${ }^{b}$, A.K.N. Reddy ${ }^{c} \&$ R.H. Williams ${ }^{d}$
}

\section{Introduction}

Energy was one of the areas of intensive debate at the $U$ nited $\mathrm{N}$ ations $\mathrm{C}$ onference on Environment and Development (U NCED) held in Rio de Janeiro in J une 1992. In A genda 21 , chapter 9 , it was agreed that current patterns of production and utilization of energy cannot be sustained, and that one of the ways of promoting sustainable development is to reduce adverse effects on the atmosphere from the energy sector. Two directions for the energy system to evolve were identified: (1) more efficient production, transmission and distribution, and end-use of energy, and (2) greater reliance on environmentally sound energy systems, particularly new and renewable sources of energy.

Notwithstanding the fact that the need for energy efficiency is widely accepted today, there is still need for an integrated view of the concept and role of energy efficiency revealing its structure and interconnections. Hence, this paper.

\section{From Sources to Services}

The objective of the energy system and its supply and utilization activities is to provide energy services, for instance, illumination, comfortable indoor climate, refrigerated storage, transportation, appropriate temperatures for cooking, etc.

The energy chain to deliver these services begins with the collection or extraction of primary energy which in one or several steps is converted into energy carriers suitable for the end-use(s). These energy carriers are used in energy end-use equipment to provide the desired energy services.

Thus far, it is the supply-side activities that have tended to attract most of the discussions of the energy sector. But, the energy system extends beyond what is conventionally considered the energy sector ${ }^{1}$ and unless the scope of the energy system is extended, energy efficiency will receive less importance than it deserves.

\section{Classification of E nergy Efficiency M easures}

The efficiency of energy conversion is one characteristic of each step of the energy chain. The energy efficiency of these conversions are quantified through the concept of specific energy use which is the energy used per unit of an energy service, for instance, in the case of refrigeration, $\mathrm{kW}$ he per litre of refrigerated volume per year; or, when the service is a product, the energy used per unit quantity of product, for instance $\mathrm{kW}$ he per $\mathrm{kg}$ of steel. Energy efficiency can be improved in each of these steps. Energy efficient technologies lead therefore to a lowering of the specific energy use for an energy service.

There are different types of energy efficient measures that can be considered in formulating energy strategies:

Institute of Electrical Engineering and Energy, University of Sao Paulo, Sao Paulo, B razil.

Department of Environmental and Energy Systems A nalysis, University of Lund, Gerdagatan 13, 22362

Lund, Sweden.

International E nergy I nitiative, 25/5 Borebank Road, Benson Town, Bangalore 560 020, India.

Center for Energy and Environmental Studies, Princeton University, Princeton, N.J., 08544, U.S.A. 
(1) more efficient extraction of primary energy and its conversion into energy carriers, for instance in power plants and refineries,

(2) more efficient transmission and distribution of energy carriers,

(3) more efficient end-use of energy in existing installations through improved operation and maintenance, and efficiency retrofits through replacement of some components, and

(4) more efficient end-use of energy in new installations, equipment, etc., through systematic deployment of more energy efficient systems and technology. These systems and technologies may be introduced at the rate of capital turnover and expansion, for instance at the rate of replacement and addition. The energy performance of new equipment varies considerably, and it is crucial to pay close attention to the specific energy use offered by different pieces of equipment for the same energy service.

\section{Reducing E nergy Service L evels in Developing C ountries is not acceptable}

This paper only addresses energy conservation measures that result in the use of less energy to provide the same energy service, or to achieve more energy services for the same energy. A $n$ illustrative example of this is the switch from kerosene wick-lamps to fluorescent tubelights in villages in developing countries. Experience from Pura village in South India shows that the household expenditure for lighting was cut in half despite the fact that illumination increased by a factor of about 19, and the energy input decreased to one ninth compared to the kerosene originally used. ${ }^{2}$ This stress on energy services is crucial in developing countries where the current levels of energy services are unacceptably low.

In contrast, energy conservation in some publications been interpreted as reducing energy use by diminishing the level of energy services, e.g., by reducing the indoor temperatures in space-heated areas to levels that require unreasonably warmer clothing. This approach to energy conservation based on a reduction of the level of energy services is not treated here. While a reduced level of energy services would also influence the total use of energy, it is associated, in developing countries, with the unreasonable request to reduce al ready unacceptably low levels of energy services, and, in industrialized countries, with the politically difficult task of asking affluent populations to depart from status quo and decrease their affluence.

\section{Technical and E conomic Potential of E nergy Efficiency M easures}

In the case of the extraction/conversion of primary energy and the transmission and distribution of energy carriers, the specific energy use can be reduced by about $10-20 \%$ ${ }^{3}$ (with respect to the energy use levels of the present average stock of equipment in industrialized countries). This reduction can be achieved by using the most efficient technologies that are available today and are cheaper than increasing supply with the present average stock ${ }^{4}$. The corresponding figure is $20-50 \%$ in the case of efficiency improvements in existing installations and $50-90 \%$ in the case of new installations. The potential for further efficiency improvements through continued research and development is large because fundamental physical constraints are distant. In developing countries, the potential for demand reduction is even larger. 


\section{Macro-economic I mpacts of E nergy Efficiency Measures}

One way of considering the aggregate impact of energy efficiency improvements on the economy is through the so-called energy-GDP correlation which may be expressed thus. Every economy consists of a number of energy-utilizing activities each of which involves an energy intensity, $\mathrm{I}_{\mathrm{j}}$, and a fraction or contribution, $C_{j}=f_{j}(G D P)$, to the GDP. Hence, the energy demand $E$ is the sum of the energy demands, $E_{j}=C_{j} X I_{j}$, of the various activities:

$$
\begin{aligned}
E & =S U M E_{j} \\
& =S U M\left[C_{j} \times I_{j}\right] \\
& =S U M\left[f_{j}(G D P) \times I_{j}\right] \\
& =\left[S U M f_{j} \times I_{j}\right] \times G D P
\end{aligned}
$$

from which we see that the Energy Demand is proportional to GDP if and only if the term [SUM $\mathrm{f}_{\mathrm{j}} \times \mathrm{I}_{\mathrm{j}}$ ] is a constant. Thus, the so-called energy-GDP correlation according to which a country's energy consumption is proportional to its gross domestic product, is valid only during periods when there is no change in the economy's (1) energy efficiency and (2) structure. If, however, there are changes in energy intensity due to efficiency improvements, process changes or product changes and/or there are changes of the contributions of different activities to the GDP (e.g., the share of basic materials manufacturing goes down and the share of less-energy intensive activities increases), the proportionality breaks down. A decrease of [SUM $f_{j} \times I_{j}$ ] can offset an increase in GDP so that the coupling between GDP and energy is reduced. There can even be a decoupling so that there is a decrease in the energy consumption associated with an increase in GDP.

The historical evidence for this reduction of coupling between energy and GDP may be obtained from the longitudinal and cross-sectional comparison of energy intensities, i.e., from a comparison of the energy/GDP (Gross Domestic Product) ratios over time and between countries. These economy-wide energy intensities have varied dramatically in industrialized countries. For example, in the U.K., the energy intensity rose during industrialization to a peak in 1880, and has then declined by about 1\% per year (Figure 1).

Similar patterns have been followed by other industrialized countries (Figure 1$)^{5}$. However, the peak energy intensities have occurred at lower and lower levels, the later in time the peak occurs. There are three factors responsible for this behaviour of the energy intensities. The first factor is the improvement over time of the efficiency of production of energy carriers -- the $\mathrm{kWh}$ her tonne of coal has improved. The second factor is the improvement of energy end-use technologies -- the specific energy use has decreased over time, i.e., the energy to perform an energy service ( $k W$ he per lumen of light) or produce a product ( $\mathrm{kW}$ he per tonne of aluminium) has decreased over the years. The third factor involves the structural changes in the use of materials whereby economies become less materials-intensive at higher levels of economic activity, leading to a less energy-intensive economy as a whole. This arises as a result of both consumer preferences shifting to more valuable, less-materials-intensive products and production shifting to better performing materials (e.g. through replacement of conventional steels with modern high-strength steels in construction) ${ }^{6}$. 


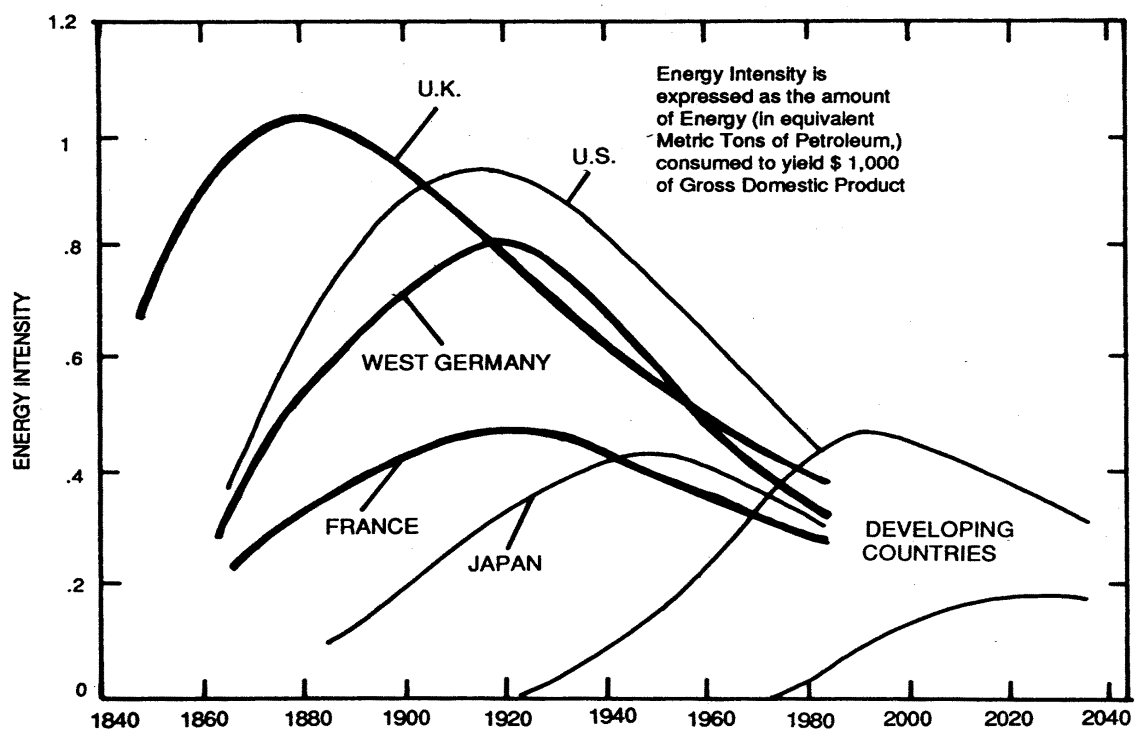

In Industrialized Countries the energy intensity (ratio of energy consumption to gross domestic product) rose, then fell. Because of improvements in materials science and energy efficiency, the maxima reached by countries during industrialization have progressively decreased over time. Developing nations can avoid repeating the history of the industrialized world by using energy efficiently.

Figure 1

\section{The Effect of Energy E fficiency Improvements on Power Sector Investments}

The power sector in developing countries is suffering from a grave capital crisis. The essence of the capital crisis is that the financial requirements of the electricity system are several times more than what can be provided by the suppliers of capital. The

"unbridgeable gap" between capital demand and supply was first highlighted ${ }^{7}$ at the level of the whole developing world by the World Bank in 1989. The Bank stated that the requests from the electricity systems of developing countries added up to $\$ 100$ billion per year in response to which only about $\$ 20$ billion was available from the World Bank and other multilateral sources leaving a gap of about $\$ 80$ billion. [These figures were revised a year later $^{8}$, but the "unbridgeable gap" remained. ]

The annual investment, I, required for expansion of installed capacity can be estimated with the following formula:

$$
\begin{aligned}
I & =E(0) \times a \times \text { gGDP } \times U C O P \\
& =E(0) \times \text { gCAP } \times U C O P
\end{aligned}
$$

where $E(0)$ is the installed capacity (in MW) in the base year, gGDP, the growth rate of the GDP, gcaP, the growth rate of installed capacity, and U COP, the unit cost of installed capacity in $\$ / \mathrm{kW}$. The term a is the ratio of the growth rates of installed capacity and GDP but from the relationship $E=$ constant $x G^{a}$ it is seen that $a=[(\operatorname{dlog} E) /(d \log G D P)]$ is the GDP elasticity of electrical capacity. [In terms of the above formula, the W orld Bank estimate of an annual investment, 1 , of $\$ 100$ billion required for expansion of installed capacity corresponds to an installed capacity in the base year 1989 of $E(0)=600 \mathrm{GW}=$ $600,000 \mathrm{M} \mathrm{W}$, a growth rate of installed capacity, gcap, of $6 \%$, and a unit cost of installed 
capacity, U COP, of $\$ 2,777 / \mathrm{kW}$ ]. As long as the product [a x UCOP] are viewed as immutable, the gGDP is in a capital trap -- it must fall if the required investments are not made.

To break out of the trap, the product [a $x$ UCOP] must be reduced. One way of achieving this reduction is through a reduction of UCOP, for example, by shifting to gas turbines and combined cycles, a shift that is already happening. A nother way -- and one that is directly pertinent to this paper -- is through efficiency improvements as follows. If $c$ is the rate of efficiency improvement, then one can write

$$
E=\left\{\text { constant } x G^{a}\right\} /(1+c)^{n}
$$

from which it follows by representing the elasticity in the presence of efficiency improvements as $a(c)=(g C A P / g G D p) c$, and the elasticity in the absence of efficiency improvements as $a(c=0)=(\operatorname{gcap} / g G D P)(c=0)$, that

$$
a(c)=\{a(c=0)-(c / g G D P)\} /(1+c) \text {. }
$$

Thus, if $c$, the rate of efficiency improvement is greater than zero, the effective GDP elasticity or the elasticity in the presence of efficiency improvements $=a(c)$ is less than the elasticity in the absence of efficiency improvements $=a(c=0)$. Hence, $c$ reduces the effective elasticity, and thereby the annual investments required to sustain a particular growth rate of GDP -- energy efficiency enables a "greater energy bang for a smaller GDP buck".

\section{E fficiency Improvements are particularly important for Developing countries}

In both developing countries and industrialized countries, cost-effective end-use efficiency improvements can take care of roughly about one third of future electricity requirements $s^{9,10}$. Energy efficiency, therefore, does not obviate the need for supply expansion, but the magnitude of supply expansion that is necessary decreases with the implementation of energy efficiency.

The quantitative potential for more efficient use of energy with already known technologies clearly indicates that there are large opportunities of energy efficiency improvements when making new investments. These are especially interesting for developing countries, because most investments in infrastructure and equipment aimed at economic growth are yet to be made.

In fact, analysis shows that by shifting to high-quality energy carriers and by exploiting cost-effective opportunities for more efficient use of energy, it would be possible to satisfy basic human needs and to provide considerable further improvements in living standards without significantly increasing per-capita energy use above the present level. For instance, the energy requirements for the W est European standard of living of the 1970s could be $1 \mathrm{~kW} /$ capita, which is only about 20\% higher than the 1986 level in developing countries. ${ }^{11}$ This is a remarkable result, which comes about because of the extremely inefficient use of energy today, especially traditional sources of energy, and because of the high energy efficiency obtained by modern cost-effective energy end-use technologies available today. With a path of development that makes use of technologies with such energy performance, energy supply need not become a constraint on development. Of course, total energy use would grow somewhat faster than population growth, and 
electricity demand would grow much faster than total energy. Primary energy use in developing countries increases from $1.11 \mathrm{~kW}$ per capita in 1980 to $1.24 \mathrm{~kW}$ in the $1 \mathrm{~kW}$ scenario, while at the same time electricity consumption increases from $39 \mathrm{~W}$ atts to 210 W atts per capita. In fact, it is this shift to electricity that is to a large degree responsible for the fact that primary energy use does not go up much (because of the better opportunities for efficiency improvement when electricity is the energy carrier).

Thus, for developing countries, there is an immense opportunity to promote measures that will permit them to avoid going through the now obsolete patterns of industrialization of the last 200 years, and instead pursue a development path that makes use of and builds on the technological know-how that now exists in the world. The use of technologies performing at least at the level of average sold technology in the North would seem a minimum requirement for technology to be transferred, or used in joint ventures. It is possible to make use of available highly efficient technologies that are applicable to the conditions of the South, for example, equipment for illumination and drives, and are less costly than the supply expansion alternative, taking into account all costs, including externalities. And, freer trade by governments around the world can facilitate this technology transfer.

\section{Technological L eapfrogging}

Developing countries should seek to utilize the best energy-efficient technologies available on the world market, if such technologies are relevant to developing country needs and cost-effective. But they should also seek specific innovative technologies and technological systems ${ }^{\mathrm{e}}$, when appropriate. The adoption of such innovative technologies is often referred to as "technological leapfrogging" (as in the children's game), whereby developing countries leap over the already industrialized countries.

Technical innovation is needed to sustain economic growth for the long term. Whereas some of the requisite advanced technologies can be obtained by the transfer of technologies developed for industrialized country markets, technologies are also needed that are better suited to developing country needs. Consider the relative prices of labour and capital. Because labour is expensive and capital relatively cheap in industrialized countries, many innovative technologies produced there are labour-saving and capital-intensive. Because labour is cheap and capital dear in developing countries, there is a need for more labourintensive, capital-saving advanced technologies.

A good example is the high-efficiency biomass power-generating technology that is to be commercially demonstrated in the northeast of Brazil $^{12}$ because the growing of the biomass feedstock on plantations is inherently labour-intensive.

Developing countries also need innovations better suited to their natural resource endowments than what they can get from industrialized countries. For example, not only is the production of biomass labour-intensive, but also biomass is more readily available than fossil fuels in many developing countries. Hence, a major energy $R \& D$ priority for developing countries should be to find ways to improve the efficiency of using biomass for energy and transforming this resource from being "the poor man's oil" into electricity and fluid fuels that are deemed attractive in modern energy markets ${ }^{13}$. M any countries in the South also have access to low-cost hydropower resources.

\footnotetext{
e Often, the largest impact on specific energy demand for an energy s ervice comes with the design of a new system.
} 
And the scales of technologies available from industrialized countries are sometimes inappropriately large for the less-developed infrastructures of developing countries.

Finally, energy needs are different from those of the North, because of differences in climate (e.g. space heating is not required in most of the South), and because satisfaction of basic human needs and infrastructure building must be given paramount attention in the South. Consequently, the innovations necessary are also different. For example, innovations in the processing of basic materials (e.g. steel, cement, glass, etc.) are needed in developing countries because such materials are needed for infrastructure-building. Y et innovations in the basic materials-processing industries will come only slowly from the industrialized countries, ${ }^{f}$ because the infrastructure-building era is largely over there, and the demand for basic materials is largely saturated ${ }^{14}$. Because such industries are so energy-intensive, innovations will tend to be less energy-intensive, as well as less costly and cleaner $^{15}$, and thus can have profound beneficial implications for future energy in developing countries.

The fundamental importance of technological leapfrogging is not widely appreciated-especially for energy. Faced with many pressing near-term crises, energy planners in developing countries are reluctant to assume the risks of innovative projects that offer only long-term payoffs. A nd many have been "burned" by past efforts to transfer advanced energy (e.g. nuclear) technology from industrialized countries. M oreover, the development assistance community has also not been supportive of innovations in the energy sector; the W orld Bank and other multilateral financing agencies finance only energy projects based on technologies with proven track records in the industrialized countries.

Because of the importance of technological innovation for development generally, and the major energy-saving benefits inherent in advanced energy conversion and utilization technologies in particular, energy strategies for developing countries should include technological leapfrogging as appropriate. U nfortunately, risks are inherent in innovation and so cannot be avoided. But foolish risks can be avoided by focusing on sets of technologies that are truly important in relation to development goals. A nd risks can be shared in various ways -- for example, if innovative projects were pursued as joint ventures between industrialized and developing country companies, and if international, multilateral and bilateral development assistance organizations were to assume some of the risks of innovating. The latter should also help build the infrastructure needed to support a dynamic innovative process in developing countries. Unfortunately, these agencies can sometimes be the barrier by insisting that, in the transfer and development of energyefficient technologies, "all technologies supplied should be well tried and proven" ${ }^{16}$.

\section{O bjections to E nergy Efficiency Improvements in Developing Countries}

It is often argued that energy use cannot be reduced in developing countries because energy consumption is al ready so low. While energy consumption levels are indeed low, the levels of energy services provided are much lower than the levels of services obtainable from the same amount of energy in industrialized countries, because efficiencies are much lower. Efficiencies are especially low for non-commercial biomass energy but are low for

Innovation is taking place in the materials industries of the industrialized countries, but this has been mainly for making value-added-intensive specially products, such as steels with special properties, pharmaceuticals, etc., rather than for basic iron and steel making, the production of basic chemicals, and the manufacture of other basic materials needed for infrastructure building. 
commercial energy as well.

It is also argued that the demand reduction is a one-time saving and therefore not significant. In response, it should be pointed out that the saving through energy efficient technologies is indeed a one-time affair with respect to installed capacity $(\mathrm{kW})$, but the saving in energy ( $\mathrm{kWh}$ ) is achieved throughout the life of the energy efficient technology. In a similar vein, it is also often argued that the one-time saving comes with the new technology, and that as economic growth continues, we would be back again on the energy growth curve. However, several observations apply to this situation. First, the energy growth curve would have a smaller slope, as the new, more efficient technology would have changed the proportionality factor. Second, the introduction of new technology is not a one-time shot. Research and development continue to offer new ways and means to obtain energy-efficient energy services. As the physical limits to energy efficiency improvements are still distant, in most cases, this process can continue for a long time. However, the critics argue, the energy growth will eventually come back. This is not necessarily true, because the composition of production and consumption changes with growing affluence, away from energy-intensive and basic-materials intensive products towards energy-efficient, knowledge-intensive products, and from products towards services in general.

It is sometimes argued that reduced expenditures on energy, resulting from energy efficiency improvements, will generate money savings that in turn, when spent, will create additional use of energy, thereby eliminating or reducing the overall impact of the energy efficiency improvement on the energy demand of a country. This is called the take-back effect However, in general, the spending of saved money would be distributed on all kinds of expenditures, thereby reducing the amount of money spent on energy to a small fraction of what was saved in the first place. In the case of minimum impact on the overall energy use, the saved money would be used only to by energy for other purposes, such as gasoline for more automobile driving. Also in this case, and overall reduction of the energy use would be there, as all activities (such as the car driving in this case) also carries costs for capital and maintenance. The take-back effect should accordingly not be overemphasized.

Finally, many believe that energy efficiency improvements would be too costly. However, in most developing countries, the costs of reducing energy use by a $\mathrm{kWh}$ with more efficient technology are invariably lower than the costs of increasing supply by a kWh through investments in new energy supply equipment. In fact, if the unit cost of supply increases are taken as the reference for comparison, then the relative costs of energyefficient technologies can turn out to be negative. The resulting reference to negative costs has led to the argument that "There are no free lunches!". But, this argument can be ignored because what is claimed is that the energy-efficient technologies correspond to a "cheaper lunch" -- more capital can be saved by investing energy efficiency compared to investing in energy supply.

There are also those who agree that are large potential energy savings that are cost-effective but believe that it is not realistic to strive to capture this potential in developing countries. For example, it has been argued ${ }^{17}$ : "Energy efficiency gains cannot be treated in isolation from the efficiency of use of other inputs and resources in an economic system. For instance, a developing society is generally at a stage of lower development only because it has not reached a level of efficiency in the utilization of its manpower, capital resources, and even natural resources. Efficiency gains in respect of any of these inputs for the 
production of goods and services require the development of institutions, human skills and infrastructure which are created only in the process of development itself".

But this argument fails to recognize that continued inefficient use of energy is simply not possible, as indicated by the capital crisis of the power sector. M oreover, even if the power sector crisis could be overcome, continued inefficient energy use would be a drag on the development process. The energy sector, and especially the power sector, are generally far more capital-intensive than other economic sectors such as manufacturing, so that continuing to squander energy makes capital unavailable for other development purposes. Finally, the argument fails to recognize that regardless of these problems, technical changes are being made all the time in developing countries by many actors, quite often at an extremely rapid pace. O ne has only to recall the explosive spread of colour television in India or even more recently cable TV. It appears that technological leap-frogging can be accelerated by simultaneous leap-frogging in entrepreneurship, institutions, management and human resource development involving capacity building. .

The pursuit of energy efficiency improvements should be carried out in parallel with improvements in institutions, entrepreneurship, management and human resource development, rather than afterward. So doing would create large opportunities for making better and wiser use of capital, human, and natural resources that otherwise would b e wasted on costly energy supply infrastructure. Emphasis on energy efficiency would liberate resources that can then be used for socio-economic development and give it a better focus.

The argument that a serious attack on the energy inefficiency problem must wait until development is further advanced is reminiscent of the view propounded by some developing country spokespersons at the 1972 UN Conference on the Human Environment in Stockholm: "We must develop first; only then can we afford to tend to the environment". The fallacy of that position is now widely recognized and is reflected in the central theme of the 1992 UN Conference and Environment and Development: that environmental and developmental goals must be pursued in tandem.

\section{Industrialized countries}

It has been long known, and has been far less disputed than in the case of developing countries, that the potential for energy efficiency improvements is large in industrialized countries. U sing the most energy efficient and cost-effective end-use technologies available, or in advanced stages of development, the energy use in industrialized countries could be reduced by the order of one half without abandoning continued economic growth. ${ }^{18}$

In many countries, considerable attention is given by utilities to demand side management as a mechanism of deferring costly investments in new energy supply. ${ }^{19}$

Also, industrialized countries are pursuing radical improvements in energy-using technologies -- the US attempt at developing in a decade's time a new automobile that is three times as fuel efficient as today's cars of comparable performance. In effect, the industrialized countries are beginning to respond to the demand of developing countries that they reduce their wasteful consumption of the world's resources. They are doing so, however, not by sacrificing energy services, but rather by pursuing energy efficiency gains that make economic sense and will help protect their environment and improve energy security. 


\section{Efficiency Improvements require a Favourable Policy Environment}

How far different energy efficiency measures should be pursued must, however, be evaluated from the standpoint of socio-economic development and environment protection. However, it is clear that energy efficiency must be the core of a genuine strategy for sustainable devel opment.

In the first place, energy efficiency is an integral characteristic of any product or activity. It is often referred to as something extra, almost like a flue gas scrubber, that is added on. But being integral characteristic implies that energy efficiency will al ways have to compete for attention when a design or investment is made. Policy formulation should start from this observation, and focus on making energy performance an intrinsic part of the continuous on-going investment process.

There are several reasons as to why most opportunities of more efficient use of energy are not routinely captured in the investment process leading, therefore, to the belief that energy efficiency improvements are not possible. For instance, there exist a number of barriers facing actors in selecting and implementing the least-cost solution from a societal perspective. ${ }^{20}$ Some barriers are associated with the fact that first-costs to capital-poor customers are prohibitively high ${ }^{9}$, that energy prices are often much less than the full costs of energy, including external social costs, that some consumers pay little attention to energy because it is not a significant expense, and that the beneficiaries of efficiency improvements are not the same as the ones that incur the investments (e.g. the landlord/tenant problem).

With respect to efficiency improvements in energy supply, including transmission and distribution, there exists in most countries a largely functioning marketplace or other incentives for an economical efficient operation. In contrast, incentives are by and large weak or non-existent in the case of energy efficiency improvements at the demand side, especially the performance of new equipment. However, there are promising ways of improving the situation in some developing and industrial ized countries ${ }^{21}$.

A key policy is to bring more energy-efficient technologies to the market, and to focus market attention on these characteristics. Several successful approaches have been tried. In Sweden, for instance, the government used its convening power to bring together the major buyers on the market for some products, such as appliances, windows, etc., where significant market fractions are bought by large buyers. A consortium of these buyers organized a competition for better products that led not only to an improvement of the products but to the buyers having a feeling of ownership. The US Golden Carrot program has applied a similar idea.

The incentive structures in the markets are of course fundamental. Integrated Resource Planning with energy efficiency as a key element took off in the US only after the

g But, the higher cost of the efficient device may be offset by the reduction in the system cost. It has been found in Sweden, for instance, that the more expensive insulation and better windows used and energy-efficient homes are now largely offset by the reduced costs for radiators under each window, and a much simpler heating system that can be installed when only small quantities of heat are required. 
regulations of the power industry were changed to make it possible for utilities to earn profits through activities on the demand side, thereby collecting the benefits for society of efficiency improvements.

$M$ easures to improve energy efficiency must be considered in all areas where energy is used. These measures would include a rationalization of energy prices directed towards prices reflecting both internal and external costs, innovative financing ${ }^{h}$, support of research and development with respect to more efficient energy end-use technologies, and the support of demonstrations and steps to create early markets for more efficient technologies. Government-organized procurement and utility-operated demand side management programs are good examples here.

The promotion of energy efficiency, at the point of energy end-use, and as built into society through the process of economic growth and investment, should be an integral part of national efforts to make energy systems compatible with sustainable development. The other element is renewable energy, where recent developments have improved the outlook for significant and cost-effective contributions to energy supply ${ }^{22}$. It is important to formulate and implement strategies, policies, programs and projects to reach environmentally sound development goals.

Fortunately, the international context is favourable for efficiency improvements. Industrialized countries which have hitherto turned a blind eye to energy efficiency issues in developing countries, are now threatened by the global environmental consequences of conventional energy strategies that ignore energy efficiency. Now, a historic shift is taking place -- industrialized countries are finding it in their enlightened self-interest to support developing country energy strategies based on efficiency improvements.

FILENAME: EFFICIEN.CY 5

$(5,907$ words $)$

16 F ebruary 1994

Based on the fact that to consumers, it is bills rather than tariffs (and unit costs of energy) that matter and therefore if ways are found of reducing bills t hrough efficiency improvements and reduced energy consumption, there will be a positive response from consumers. 
References

1... Goldemberg, J., J ohansson, T.B., Reddy, A.K.N. and W illiams, R.H., Energy for a Sustainable World, Wiley-Eastern Limited, N ew Delhi, 1988.

2... Reddy, A.K.N., Electricity Planning: Current Approach and Resulting Problems, M odule M 2, Course M aterials for Workshop for Policy-makers on Electricity Planning and Development, January 4 \& 5, 1994, International Energy Initiative, Bangalore.

3... In power generation, the potential savings for extraction/conversion plus transmission/distribution may be much larger than $10-20 \%$,; they may even be 10 $40 \%$. The incremental heat rate for cogenerated power is $30-40 \%$ less than for power provided in central station power plants. And for central station power plants, the most energy-efficient technology now on the market is the ABB GT26, a $240 \mathrm{M} \mathrm{W}$ combined cycle involving an advanced reheat gas turbine. The heat rate of this combined cycle on natural gas is $6160 \mathrm{~kJ} / \mathrm{kWh}$ (58.5\% efficient), L HV basis or $6840 \mathrm{~kJ} / \mathrm{kWh}$ (52.7\% efficient). a HHV. (ABB intends to sell these combined cycles for $\$ 500 / \mathrm{kW}$.). For comparison, the average heat rate for oil and gas-fired power plants in the US was $11,320 \mathrm{kj} / \mathrm{kWh}$ (31.8\% efficient), HHV basis. The introduction of fuel cells in distributed configurations will not only lead to high conversion efficiencies, but also to much larger markets for cogeneration.

4... The comparison of the costs of efficiency improvements with the costs of expanding energy supply does not take into account external costs (for example, environmental costs) associated with energy supply.

5... Reddy, A mulya K. N. and Goldemberg, Jose, Energy for the Developing World, Scientific American, V olume 219, (1990) 110-119.

6... Williams, R.H., Larson, E. and Ross, M., Materials, Affluence, and Industrial Energy Use, Annual R eviews of E nergy, V olume 12 (1987) 99-144.

7... Churchill, A.A. and Saunders, R.J., Financing of the Energy Sector in Developing Countries, 14th Congress of the World Energy Conference, M ontreal, 14-22 September, 1989.

8... The numbers were updated a year later by E. A. M oore and G. Smith in an official W orld Bank publication Capital Expenditure for Electric Power in the Developing Countries in the 1990s, Industry and Energy D epartment W orking Paper, Energy Series Paper 21, World Bank, 1990. It was projected that installed capacity in developing countries would increase from $471 \mathrm{GW}$ at the end of 1989 to $855 \mathrm{GW}$ at the end of 1999 in developing countries (average growth rate of 6.1\%/year). Also the total cost in constant dollars was somewhat less than earlier indicated: $\$ 757.5$ billion $1989 \$$ for 10 years or $\$ 76$ billion per year or $\$ 1970$ per kW of generating capacity (of which $\$ 1200$ per kW is for generating capacity).

9... Bodlund, B., M ills, E, K arlsson, T. and Johansson, T.B., The Challenge of Choices: Technical Options for the Swedish Electricity Sector in J ohansson, T. B., Bodlund, B. and W illiams, R.H., Electricity -- Efficient End-Use and New Generation Technologies, and Their Planning Implications, L und U niversity Press, 1989.

10... Reddy, A.K.N., Sumithra, D.G., Balachandra, P. and D'Sa, A., A Developmentfocused End-use-oriented Electricity Scenario for Karnataka, E conomic and Political Weekly, Volume XXVI, A pril 6 and 13, pages 891-910 and 983-1001.

11... Goldemberg, J., J ohansson, T.B., Reddy, A.K.N. and W illiams, R.H., Basic Needs and Much More With One Kilowatt Per Capita, Ambio V olume 14 (1985) 190-200. 
12... Elliott, P. and Booth, R., Brazilian Biomass Power Demonstration Project, Special Project Brief, Shell International Petroleum Company, London, 1993.

13... J ohansson, Kelly, Reddy, and Williams 1993

14... Williams, Larson, and Ross 1987)

15... Goldemberg, Johansson, Reddy, and Williams 1988)

16... UN doc. E/C.13/1994/5, para 8. -- Report of the Secretary-General, Energy and Sustainable Development: Efficient Utilization of Energy Resources. Means to promote and implement energy efficiency in developing countries.

17... Pachauri, R.K., Energy and Development, K eynote A ddress, O pening Plenary Session, Division 3, 15th Congress of the World Energy Council, M adrid, 20-25 September 1992.

18... Goldemberg, J. et al, Op. cit. Reference 1.

19... B Bob -- a good review paper to reference here??

20... Reddy, A.K.N., Barriers to improvements in energy efficiency, E nergy Policy, Volume 19 (1991) 953-961.

21... Williams, R.H., Innovative Approaches to Marketing Electric Efficiency, in J ohansson, T.B., B odlund, B. and Williams, R.H., Electricity -- Efficient End-Use and New Generation Technologies, and Their Planning Implications, L und U niversity Press, Lund, Sweden, 1989.

$22 \ldots$ Johansson, 